\title{
The Role of Trust in Knowledge Management: A Case Study of Physicians at Work at the University Hospital of Northern Norway
}

\author{
Gunnar Ellingsen \\ University of Tromso, Tromso, Norway
}

\author{
Gunnar.ellingsen@unn.no
}

\begin{abstract}
The knowledge management literature suggests that reuse of externalized knowledge is fundamental for improved efficiency, reduced costs and reduced dependency on individual know-how. Rather than considering knowledge as a specific thing the paper relates knowledge to the work people do. It suggest that knowledge management literature avoids to take into account how knowledge needs to be made credible, relevant and trustworthy in order to be used across time and across different contexts in large organizational contexts. The paper analyses how work is needed to render knowledge trusted through patient trajectories and how different contexts, people and situations shape the comprehension of trust associated with existing knowledge. Empirically, the paper draws on different medical contexts at the University Hospital of Northern Norway.
\end{abstract}

Keywords: trust, knowledge management, knowledge work, patient trajectory

\section{Introduction}

A common argument today is that many organizations have become so complex that their knowledge is fragmented, difficult to locate and share, and therefore redundant, inconsistent or not used at all (consider for instance Zack, 1999). There are also arguments about increased market competition, which make it necessary for organizations to focus on knowledge as an important resource. According to these arguments, knowledge creation, representation and diffusion are key mechanisms in ensuring modern companies' and organizations' competitive advantages (Blackler, 1995; Davenport and Prusak, 1998).

Aligned with a relatively high share of the knowledge management literature, this knowledge is associated with so-called knowledge-intensive firms and their knowledge workers (read for instance Alvesson, 1995). In this way knowledge is considered a property of the firm or a specific entity (Blackler, 1995) that typically is stored in large databases as externalized and codified know-how. At a later stage, it is assumed that this knowledge will be readily reused in various contexts associated with the firm.

Material published as part of this journal, either on-line or in print, is copyrighted by the publisher of Informing Science. Permission to make digital or paper copy of part or all of these works for personal or classroom use is granted without fee provided that the copies are not made or distributed for profit or commercial advantage AND that copies 1) bear this notice in full and 2) give the full citation on the first page. It is permissible to abstract these works so long as credit is given. To copy in all other cases or to republish or to post on a server or to redistribute to lists requires specific permission and payment of a fee. Contact Editor@inform.nu to request redistribution permission.
Considering the knowledge concept as outlined above is both narrow and too optimistic. Several studies have reported the shortcomings of such a perspective and pinpointed that it is essential to take an alternative or broader approach (consider Knorr-Cetina (1999), Atkinson (1995) and Hunter (1991), to which this work also adheres). From this point of view, it is insufficient to focus on knowledge as a thing; the focus must rather be how people create knowledge and how knowledge is made sufficiently trusted in order to be used 
across contexts. Atkinson (1995:45), for instance, places emphasis on medical knowledge production as work. This work is achieved not only through the content of collegial talk, but also through the form of that talk. Thus the knowledge creation and translation process is not only based on journals and textbooks (Atkinson, 1995:90-91) but also includes talks between colleagues such as clinical lectures; ward rounds; morbidity reviews; and a surgeon's comments to juniors and students.

The study reported in this paper focuses on physicians' work in four different contexts at the University Hospital of Northern Norway (UNN) when they produce discharge letters. At UNN the discharge letters are an important part of the hospital's electronic patient record, accordingly placing this study at the core of the hospital's most critical information system. In contrast with the traditional view on knowledge work (Alvesson, 1995) clinical work, and especially as practiced at large hospitals like UNN, is highly specialized. It is characterized by state-of-the-art knowledge, high levels of education and organizational complexity.

As knowledge originates from a myriad of different contexts and information sources, a large part of knowledge work in hospitals involves summing up and thus reusing previous information (Berg, 1998:298). It underscores the importance of historical knowledge as a foundation for present action and for future knowledge creation along the patient trajectory. The term "trajectory" refers not only to the physiological unfolding of a patient's disease but to the total organization of work done over that course, plus the impact on those involved with that work and its organization (Strauss et al. 1985:8).

The work done on patient trajectories is highly specialized and distributed (Strauss et al. 1985:26; Blume, 1991:17; Atkinson, 1995:7; Reiser, 1984:303). This points out that work in hospitals is extremely interdependent and accordingly emphasizes the role of trust as expectations about another's trustworthiness become relevant when the completion of one's own activities depend on the prior action or co-operation of another person (Lane, 1998:3).

Moving beyond simplistic dichotomies, such as tacit/ explicit knowledge representations, I dwell on the practices for rendering knowledge (regardless of representation) credible, relevant and trustworthy. It is not immediately obvious which forms of knowledge are credible and which are less so as "all too often, data present themselves in ways not anticipated...or data items deemed trustworthy suddenly behave unexpectedly" (Berg, 1997:141). Sorting this out involves work during the different patient trajectories. Thus the aim of this paper is to identify the conditions for how and when knowledge is made trustworthy and in what shape. More specifically, the analysis is pursued along two themes:

First, I analyze how trust depends on different knowledge sources and different contexts. Atkinson (1995:127) points out that "Not all knowledge is treated as having equal value. It has different sources, and has different weight attached to it, and may be regarded as more or less warranted". This corresponds with Cicourel (1990:222) when he argues that "the perceived value of medical information is related to the perceived credibility of the source". This means that trust in knowledge might fluctuate with who has produced it, where it is produced and how it is produced.

Second, I analyze how trust is shaped by patient trajectories. Trajectories point to the actual work involved in medical knowledge production. Medical work is hectic and has to deal with a lot of emergency cases as well as complicated patients with uncertain diagnosis and prognosis (Hunter, 1991:28; Atkinson, 1995:111). The produced documents in the patient record are shaped accordingly - they reflect what the physicians at a given moment 'know'. This means that knowledge that currently is trusted might easily transform into irrelevance and untrustworthiness.

The remainder of this paper is organized as follows: the next section elaborates more thoroughly on the theoretical foundation and is followed by a reflection on the research design. After that three case vignettes which present physicians' work in different departments are outlined. The last two sections con- 
tain the analysis and the conclusion. The conclusion contains implications for information systems design.

\section{Theory}

In some of the IT literature knowledge is defined by categorizing it into 'data', 'information' and 'knowledge'. From this viewpoint 'data' is a set of objective facts with no associated purpose (Davenport and Prusak, 1998:2). 'Information' is more value-oriented. 'Knowledge' is considered to possess key properties like experience, truth and judgement, and is typically associated with so-called knowledge-intensive firms (Alvesson, 1995:6). It is argued that such companies, including their knowledge workers, are characterized by: frequent problem solving; creativity; reliance of individuals; high levels of education; and a high degree of professionalism. This is an aspect of knowledge that falls into a category that Blackler (1995:1023) denotes as 'embrained' knowledge and promotes knowledge exclusively as a specific entity (Blackler, 1995:1033) that even is tradable.

Information technology is considered to have a central role in organizing knowledge, both in order to enable sharing and collaboration, and more explicitly through the storing and categorizing of different knowledge units which can later be retrieved and presented as meaningful across contexts. This kind of knowledge is generally described as explicit and is possible to codify. Tacit knowledge on the other hand is individual and context-specific and is accordingly hard to formalize (Nonaka and Takeuchi, 1998:218). Enabling the transition from tacit to explicit knowledge both in order to enable collaboration as well as to make it conform more to information technology is considered to be a major challenge.

A growing amount of literature argues that a broader approach to the knowledge concept is necessary. This implies relating knowledge to practice or as something people do (Blackler, 1995:1023; Brown and Duguid 1991:40; Czarniawska 1997; Knorr-Cetina 1999:8). In order to underscore the complexity around the issue Blackler (1995) categorises knowledge as embrained, embodied, encultured, embedded and encoded. He further underscores that the implication is that not only limited groups (read Alvesson (1995)) are regarded as knowledge workers, but that all individuals and all organizations are knowledgeable (Blacker, 1995:1026). Being a knowledge worker thus means being involved in learning and the creation of new knowledge through becoming an 'insider' in the community (Brown and Duguid, 1991:48), that is, they are acquiring not explicit, formal 'expert knowledge', but the embodied ability to behave as community members. Knorr-Cetina (1999:1) extends this by arguing,

"By many accounts, Western societies are becoming "knowledge societies", and "a knowledge society is not simply a society of more experts, more technological gadgets (...) it is a society permeated with knowledge cultures, the whole set of structures and mechanisms that serve knowledge and unfold with its articulation"

One such society is the medical context. As a complex organization, there are good reasons to look more closely into how and when and under which conditions knowledge is trusted and thus possibly used and reused.

Medical work is recognized with more or less expected tasks. This is by no means exclusively associated with the medical context. In general all work-industrial, commercial, artistic, domestic-involves a sequence of expected tasks (Strauss et al. 1985:9). In medical work, however, the term trajectory has been suggested to conceptualize the chain of tasks and the knowledge associated with the course of illness of a patient. Trajectories point to the fact that patients follow a trajectory that refers to a past, a present, and a possible future (Timmermans and Berg, 1997:276). Trajectory is not only a term used for the course of illness, it includes also the heterogeneous amount of knowledge work conducted on the course in order to cope with the illness of the patient. This work is illustrated when physicians produce dis- 
charge letters where ongoing summations construe "histories" and "futures" that are continuous with the present (Berg, 1997:136).

A factor that influences the complexity of medical work is its richness and messy character (Atkinson, 1995; Strauss et al., 1985; Berg, 1998) and its continuous uncertainty (Hunter, 1991:28; Atkinson, 1995:111), which implies that medical work is the continuous struggle to make a patient's case work: to keep a patient's trajectory “on track" (Berg, 1997:127).

Related to patient records, this uncertainty translates into making problems manageable within the hospital's working routines as:

“Through [the physician's] activities of reading and writing...he narrows down the plethora of potential tasks and divergent data into a clear notion of "what to do next"' (Berg, 1996).

Thus, making patients' problems manageable is an ongoing, active process of articulating a broad array of diverse elements. It is characterized by the smooth interweaving of "social" and "medical" issues, and by the constructed nature of medical data and criteria. It is thoroughly temporally structured: all activities are located within a trajectory's projected "history" and "future", both of which are continually reconstructed (Berg, 1997:137).

An important part of problem solving in hospitals is related to determining the diagnosis of patients. In simple cases a disease will be easily recognizable when its major symptom is readily apparent, but in many other cases the diagnosis is far more complex (Hunter, 1991:70), which implies that medical work is the continuous struggle to make a patient's case work: to keep a patient's trajectory "on track" (Berg, 1997:127). This makes the term "managing" the problematic trajectories difficult as diagnoses might be difficult to assess and courses of illness may be difficult to predict. Strauss et al. (1985:20) has suggested that problematic trajectories is better understood as "shaping" them, that is, handling the contingencies as best one can, although being far from fully in control of the trajectory.

In difficult cases "the routine trajectory turns into a non-routine and, also, often highly problematic one then trajectory management begins to get shared with other medical specialists" (Strauss et al. 1985:26). Consequently, the knowledge shared among the healthcare personnel must be considered reusable and trusted. The combination of highly distributed work with uncertainty and complexity brings fully in the element of trust as it reduces complexity as well as fostering collaboration.

The dichotomous distinction heralded by Nonaka and Takeuchi (1995) between so-called tacit and explicit knowledge side-steps the key issue of describing the work, efforts and strategies of rendering knowledge understandable, credible and trustworthy. Large organisations, including large hospitals, need to cope with what Giddens (1991: 21) argues to be an increasingly important aspect of the modern world and describes as "disembedding", that is, "the 'lifting out' of social relations from local contexts of interaction and their restructuring across indefinite spans of time-space". An essential aspect of this is how processes of "re-embedding" need to re-establish social links, networks and communities of practise.

As convincingly demonstrated in later studies in knowledge management, externalised materialisations of knowledge (likely to face "disembedding") require a social embedding (Lam 1997; von Krogh, Ichijo and Nonaka, 2000). The question, then, is how do organisations preserve the deeply social aspects of knowledge production under the increasing pressure of disembedding processes? On Giddens' (1991: 79-80) account, modern societies and organisations have to increasingly trust "abstract systems" implying "faceless commitments". Hence, this delegates a pivotal role to establishing, maintaining and extending trust as a necessary basis for knowledge work and knowledge cultivation.

Two definitions of trust are commonly found in management literature; one that defines trust as predictability, and one that emphasizes the role of goodwill Hardy, Phillips and Lawrence, 1998:64). The first 
definition, trust as predictability, points to that trust ensures that you can count on knowledge produced in specific context by specific people or as Bachman (2001:342) emphasizes, "trust reduces uncertainty in that it allows for specific (rather than arbitrary) assumptions about other social actors' future behavior." The second definition argues that trust is more than predictability: it also includes goodwill, the existence of common values that can be translated into common goals (Hardy, Phillips and Lawrence, 1998:68). However considering trust in terms of both predictability and goodwill presupposes that predictability arises from shared meaning, while goodwill arises from the participation of all partners in the communication process whereby this shared meaning is created (ibid.:69). Accordingly, trust can be considered a continuos process of sense-making and negotiating that bridges heterogeneous groups. In that way can trust play a role where rational prediction ends as trust possess the power of bridging information uncertainty" (Lane, 1998:6).

The kind of trust involved in knowledge work is not a static entity either present or absent. Nor is trust unlikely to emerge spontaneously and, so, we need to learn how to create trust between actors with very different goals and values (Hardy, Phillips and Lawrence, 1998:65). Consequently, trust is a performed achievement of a concerted and highly heterogeneous effort with actors, artefacts and other externalised knowledge representations. As pointed out by Cicourel (1990:222), "the perceived value of medical information is related to the perceived credibility of the source". An important aspect of knowledge work, then, is to unpack how disembedded or externalised knowledge is rendered credible and trustworthy. This problem is dramatically reinforced in settings, including modern hospitals, with extensive generation of externalised knowledge.

\section{Method}

This study belongs to an interpretative approach to the development and use of information systems (Klein and Myers, 1999; Walsham, 1993) relying on four types of data: participative observations; interviews; informal discussions; and documents. The observations took place from January-March, 2001 in four departments at the University Hospital of Northern Norway. The hospital has 600 beds and has approximately 4000 employees (400 physicians and 900 nurses)

In total, 42 hours were spent observing work. In addition, from March-February, 2000 I conducted 19 hours of observation in three other departments which were used as background material.

Predominantly the study can be denoted as 'realistic' as it focuses on 'thoroughly mundane details of everyday life among the people studied' such as 'the regular and often-observed activities of the group under study' (Van Maanen, 1988:48). It is in part also inspired by the 'impressionist' style as I try to give the story's supporting players lines to speak (ibid.:105).

In the four present departments the observations were especially aimed at work situations for physicians as they are recognized as a particularly important user group. Nevertheless, in some situations secretaries became involved, and in some meetings nurses were part of the group. On occasions, also patient examinations were observed.

As a part the observation I found it useful to be in the on-duty room waiting for something to happen. The first time however I showed up in ordinary clothes whereupon a nurse relatively quickly approached me asking me who I was and the reason for my presence. I explained it to her and told that that this was part of the deal with the department. This was not a unique experience. While sitting there, health personals entered the room talking with each other, discussed, asked for information etc and quite noticeable lowered their voice or kept quiet, sometimes looking at me. The following day I tried another approach and borrowed a white physicians coat before I entered the ward. This meant that I was now dressed like a health care worker; I might even pass for a physician with his badge lost. The experience 
was very satisfactory as I no longer was aware of any reserved attitude and nobody asked me why I was there. It was also easier to ask questions about what happened and why.

I was allowed to move freely around in the wards. I participated in several morning meetings with physicians and nurses and participated in coffee- and lunch breaks, I joined groups of physicians discussing in corridors, on-duty rooms, examination rooms and pause rooms. In one department, I also observed several patient examinations. Sometimes I "shadowed" willing physicians in their work. In these situations I could pose questions in order to clarify and elaborate observations. The extent and format of these obviously varied with what was possible without intruding too much with ongoing work. Questions were postponed when the work was recognized as hectic, during formal group meetings or in front of patients.

People did not seem to mind being observed. This resulted in a fluctuation between a fairly passive role merely observing as non-obtrusively as possible and a more active role, when possible, posing questions for clarification and explanation. All together there were 34 semi-unstructured interviews during the periods mentioned above. Each interview lasted from 1-2 hours.

\section{The Cases}

Medical practice varies enormously - within different domains, departments, hospitals and countries (Atkinson, 1995; Strauss et al., 1985; Berg, 1998). I have no ambition of paying justice to this variation in any systematic or comprehensive manner. Rather, I merely aim at expressing an appreciation of this variation through a sampling of 3 wards at UNN. All the observations are targeted at the process of producing and receiving discharge reports. Characteristic features of these work situations in the different contexts are:

- Dept of Cardiac and Thoracic Surgery: An extremely hectic high-specialised department with relatively narrow problems of concern. Most of the patients have had a full investigation in another department.

- Section of Nephrology, Dept of Medicine: A section with a lot of control patients related to chronic diseases. As a part of the whole Dept of Medicine however, the physicians experience a relatively high share of emergency cases with pretty unclear problems.

- The Dept of Oncology: Most of the daily operations of the department are planned but due to complex diagnoses, the physicians have to deal with a high degree of uncertainty.

\section{Department of Cardiac and Thoracic Surgery - Hectic and Highly Special- ized}

The Department of Cardiac and Thoracic Surgery is responsible for cardiac surgery for adults in the Northern Health Region of Norway. Most of the patients admitted to the department have received in advance a full examination by another department or (local) hospital. The patients normally stay for six days. After their surgery they are transferred to another department within the hospital or to a local hospital. In this situation it is imperative to include the discharge letters in order to inform others of the patient's conditions, medications and further follow-up. The following vignette illustrates the work in the department:

About 10 persons are present at the morning meeting, one head physician and three assistant physicians, the rest are nurses who enter and leave the room depending on whether 'their' patients are involved. The discussions circle around the patients' heart surgery. The atmosphere appears hectic and effective. Any disagreements about changes in prescribed medications, further treatment strategies and whether patients are capable of leaving today are quickly settled. 
One of the assistant physicians, Pasi, breaks from the morning meeting in order to produce a discharge letter on a patient that is leaving today. He goes to the on-duty room bringing with him the paper-based patient record which he places on a desk. First of all he picks out the admittance report and the surgery report from the previous day. He also picks out and reads the discharge letter from a stay at the Department of Medicine one month earlier where the patient has had a full examination prior to his surgery.

The on-duty room is busy and crowded. Physicians and nurses pass through all the time contributing to a hum of questions, advice and discussions. The phone is constantly ringing. This is the place where Pasi usually dictates the discharge letters. While ignoring the noise around him, he starts to dictate the social status for a patient that has had heart surgery: "72 years old fisherman that lives together with his wife...". The dictation becomes very short. And as one of the head physicians puts it "It has to be short in order to quickly point to what this is all about". In his dictation, Pasi did not reuse the summary from the admittance report (as some do). He says: "I use it if it is good, but not always. Anyhow, most of the time goes to obtaining an overview of the case and then I have to read in the patient record. It might be that documentation produced some time ago is important. Surgical and medical texts are also very different, which means that sometimes I have to turn to old documentation to get the whole picture". He also tells that as a very inexperienced assistant physician at this department, he often had to read for 2 hours to get an overview of a case.

He continues to dictate. It is rather staccato since he tries to make sense of information from several sources, both from the pile of papers as well as from the electronic patient record. He realizes then that he needs the patient chart. He stops dictating, walks to one of the examination rooms, finds the chart and continuous to dictate. He also reads and picks information from the nurse report. Once more, he stops dictating, and goes to the patient in order to measure her talus arm index. One moment later he is back and comments "no pulse in the foot, there is better circulation in the minor arteries, but not in the large ones". As the last point, he has to check whether the patient needs to be summoned to a control. He leaves the room, searching for the chief physician. He finds him in one of the patient rooms, gets the necessary information and finishes the dictation.

\section{Section of Nephrology, Department of Medicine - Specialized Work for Chronic Patients}

The Section of Nephrology is a part of the Department of Medicine. The section has a lot of control patients related to chronic diseases such as kidney failure who come for periodic controls. In addition, as a part of Department of Medicine, the section has to relate to a lot of emergency patients with unclear problems. Presented below is work from an experienced physician.

In an office in the Dept of Medicine a physician is making himself ready to produce discharge letters. The patients involved have been discharged from the hospital a couple of days ago. On the desk, in front the physician, there is a pile of patient records and one computer. On the front cover of several of the paper records "RETURN DIALYZE" is written in large letters. This means that these paper records are stored in the Peritoneal Dialysis-section in a special archive. Patients having these records come regularly as they are special patients. As a result, only the secretaries in the Peritoneal Dialysis-section write these letters in order to ensure that everything is done right.

Laboring through his workload, it becomes clear the several of the cases are quite complex: unscheduled emergency cases, several examinations in other departments, contacts with psychiatric sections or relying on results from several laboratories. He keeps pausing to check information from several sources: blood results from the laboratory system; running notes from the electronic patient record; results from referrals; and patient charts from paper records. Together they consti- 
The Role of Trust in Knowledge Management

tute pieces in a puzzle that need to be assembled, evaluated and assessed closely with the patient's current condition.

He reads extensively. Reading and dictating are interleaved. The physician also needs to consult a couple of his colleges by phone.

For some of the patients he accesses the electronic $x$-ray system. He studies the $x$-ray pictures and examines the $x$-ray reports before making a summary of it on the fly while dictating. He also includes his own assessments. Retrospectively explaining he states that "Sometimes I can cut and paste from parts of the x-ray report. It depends on how much of it is important".

One of the discharge letters is based on an emergency admission. This time he dictates partly the same information that is in the admittance report (located in the electronic patient record). He explains that the reason he did not instruct the secretary to reuse the first sections was because the information

\begin{tabular}{l|l} 
Date & $\mathbf{1 0 . 0 1 . 0 1}$ \\
\hline Estimated dry weight & $87-88 \mathrm{~kg}$ \\
\hline weight & $87-88 \mathrm{~kg}$ \\
\hline Quantity of urine & $2000 \mathrm{ml}$ \\
\hline Quantity of dialyse solution & $12730 \mathrm{ml}$ \\
\hline Ultra filtrate & $1000-1400 \mathrm{ml}$ \\
\hline Blood pressure & $172 / 106$ \\
\hline KT/V -own & 1,16 \\
\hline \multicolumn{1}{c}{-total } & 3,09 \\
\hline Kreatin-clearance & $74,61 /$ week \\
PET & Not performed at this stay \\
\hline Prealbumin/albumin & 35 \\
\hline HB & 12,6 \\
\hline iron & 17 \\
\hline TIBC & 62 \\
\hline ferritin & 205 \\
\hline Ca /ion. Calcium & $2,36 / 1,22$ \\
\hline Phosphate & 1,92 \\
\hline PTH & 20,4 \\
\hline Bag strength & CAPD bag strength Locolys 2,3 \% 4 x 2 \\
& liter at day time, 2,5 liter Extraneal at \\
night time
\end{tabular}

Figure 1 The Peritoneal Dialysis form in the admittance report was incorrect. He had to correct this information based on conversations with the patient and his wife. He also studies the nurse reports and says: "You have to do that often to check whether it says something important, well ...nothing important this time". For the next patient, however, the physician instructs the secretary to copy from named sections of the admittance report. Now the secretary will reuse this text. The physician explains afterwards that he knew what the documentation contained because he had dictated this admittance report himself.

The final patient is a chronic Peritoneal Dialysis patient. In addition to the dictation he retrieves the patient's completed Peritoneal Dialysis form (see Figure 1) from the computer. He copies it and pastes it into the discharge letter. It contains a lot of important measurements related to the patient's condition. And, as he says, "This is a patient that regularly returns to the section and he needs clear cut rules for who is responsible for what".

\section{The Dept of Oncology - Collective Sense-Making}

The Department of Oncology is the only one in Northern Norway and has the major responsibility for cancer treatment in the region. Most of the patients are examined at a local hospital before they are admitted to this department. Due to the nature of the disease, some of the patients are hospitalized for a relatively long time. Others, depending on the treatment protocols, receive periodic treatment such as radiation or chemotherapy. This makes most of the daily operations planned. The personnel experience however a very hectic work environment during the day as a result of the large percentage of extremely complicated patients. We follow an assistant physician with four months experience.

We are in the assistant physician's office outside the ward. It is six o'clock in the afternoon. It is quiet. The room is semi-lit. The computer screen beams brightly at the desk. The daytime work- 
load makes discharge letter production prohibitive. They end up as evening activities and are dictated in her office. The physician is relaxed, neither the beeper nor the phone interrupts the work and at regular intervals she allows time to explain what she is doing.

The discharge letters from this department are extensive. There is little given structure to the text; they come close to free-text descriptions. The first patient is a newcomer, requiring extra time to study. She spends some time going through the paper record as well as retrieving information from the electronic patient record. She dictates extensively, describing the current situation for the patient. She logs onto the electronic x-ray system and reads the CT-description, makes a summary of it and continues to dictate. Part of her dictation shows that during the stay the physicians have discussed possible treatment alternatives. The patient has also been involved in these discussions and has insisted on trying a special treatment that the patient has become aware of that may have an effect on his diagnosis D1. The patient is now discharged from the department without any documented effect of the current treatment.

After the stay, the physicians have continued to evaluate the case and have agreed to invite the patient to an ongoing research study outside the given protocol. This implies that the patient will receive treatment $\mathrm{T} 1$. A complication is that the patient may also suffer from diagnosis $\mathrm{D} 2$. If so, normally treatment T2 would have been given, but the physicians have never previously combined treatment T1 and T2. One of the involved head physicians recommends that they order treatment T1 (and not treatment T2) even if the patient also suffers from D2.

The assistant physician works over half an hour with this discharge letter, producing two pages of closely spaced text. Afterwards she explains that they treat many different types of cancer, some of which are rare for general practitioners. It is therefor difficult to know what to be aware of, for instance possible side effects of certain treatments. These are rather specialized things that should be included in the discharge letters.

\section{Analyses}

\section{Trust in Knowledge Sources}

Collaboration in complex organizations presupposes trust (Atkinson, 1995:118; Davenport and Prusak, 1998:34-35). Trust is related to how and when information is achieved and to personal experience. Knorr-Cetina (1999:97-98) denotes it:

"the acting body...[where] sensory performance and action go together...[From this viewpoint] the body is trusted to pick up and process what the mind cannot anticipate."

Knorr-Cetina (1999:131) argues that 'trust' classifies participants in terms of what is known about them, that is whose work can one build upon and whose results are believable - a point also made by Smith (1990:217) related to trust in textual sources. The degree of trust, in information from the patient's chart or advice given, depends very much on whose observation or opinion it was (Atkinson, 1995:57). This draws an important distinction between experts and non-experts (Knorr-Cetina, 1999:131) or the distinction between head physicians and assistant physicians as:

"If it is some of the regulars that have produced the summary then I might accept it at 'face value' and use it as is. But if it is produced by an inexperienced physician then I have to read more thoroughly to check whether it can be used."

The assistant physicians can be complete novices, just graduated from medical school, or they can have several years experience within other fields but are completely new to the current one. The implication, regarding the content of the admittance reports may be as follows: 
"Often it is the novices that receive the patients [which means] that assessments can be turned around the following day and thus resulting in worthless summaries" (physician, Section of Nephrology).

This implies that the assistant physicians' current trustworthiness has to be built and reinforced. One way of doing this is through alliances with head physicians, as is the case in the Department of Oncology when the assistant physician lends force from a head physician when further treatment of a patient has to be decided.

In complex collaboration forms it is however not only persons that must be trusted. Also certain contexts and being a part of that context ensure better trustworthiness. Consider the practice at the Section of Nephrology and their use of the Peritoneal Dialysis form:

"We have dialysis-patients that come in regularly for treatment, and every time there are certain things that must be carried out...partly some extremely important computations which indicate if it is necessary to change modus and whether their medication is sufficient....We paste the results into the discharge letter."

First, the quote illustrates the unpredictability for work along a trajectory and underscores that the trajectory is continually reset on the spot as the outcome of the continual articulation work of physicians and nurses concerning their own subtasks and of the subtasks performed by the medical record and the laboratory routines (Berg, 1997:138). Second, the quote emphasizes that for these chronic patients, it is in fact imperative to reuse the computations to ensure proper quality. It is also enabled by a reasonable level of overview of what is going to occur with the patient during the stay. In these cases, trust is not only related to physicians, but also to the particular context. This is the only place where these records are archived and only the secretaries in this section are trusted to write these letters.

Different degrees of tacit knowledge between communities might also hamper knowledge sharing. Some knowledge may not be migratory because it is highly embedded in complex social interactions and team relationships within organizations (Lam, 1997:974-975) as is illustrated from the receiving end of the discharge letters (among the general practitioners):

"Sometimes we receive discharge letters from highly specialized departments where it is difficult to know what the conclusion is; whether the patient has as disease or not. A specialist can read more between the lines ... but to a general practitioner, it is not clear what the assessment is and how close the patient is in the process towards a diagnosis or the current status of the treatment" (general practitioner).

In some contexts, a high share of the knowledge only exists in an oral and distributed form as is the case when Pasi at the Department of Cardiac and Thoracic gathers information for the discharge letter. The discharge letter is not only based on existing documents but also on solely verbal accounts. Pasi gathers necessary information from the morning meeting (such as current status, change in medications and further treatment strategy) as well as halting his dictating in order to ask his colleagues about follow-up information. He also stops in order to measure the patient's talus arm index, which shows that knowledge is produced 'in-the-making'.

The on-duty room in Pasi's department also serves as an illustration of how knowledge is orally produced and reproduced. Physicians and nurses regularly come and go, they ask questions, discuss cases, coordinate activities, talk on the phone with patients, etc. Knowledge is then created through a collective process in a community (Brown and Duguid, 1991:46) and trust is ensured by being a part of this community (Van House et al., 1998:339). Such a context contains discourse that transforms individual knowledge into a sort of distributed cognition or a stream of collective self-knowledge recognized by a constant humming with itself about itself (Knorr-Cetina, 1999:173). 


\section{Trust and Patient Trajectories}

Producing discharge letters implies reading textual documents like previous running notes, admittance reports, etc. A basic point with reading such texts and thereafter reusing them is to understand their content. The chief physician in the Department of Ear, Nose and Throat underscores that

"the conditions for systematic reuse are existing documents that are brief, concrete and simple." Such documents are shaped by the context where they are produced. As the context in Department of Ear, Nose and Throat illustrates, when the context is relatively self-contained, a narrow set of diseases and with patient cases that are relatively clear set the potential for reuse of knowledge increases. In fact the knowledge in this department reflects a certain stability and then the knowledge, as the chief physician argues,

"becomes first-hand facts as it is very much in accordance with what really happened during the stay rather than producing a story out of it afterwards."

In this way, a high degree of knowledge reuse is associated with a known context as trustworthy elements exhibit the most predictable and unequivocal behavior (Berg 1997:95). Knorr-Cetina (1999:97) uses the notion of 'acting body' as a way to increase understanding and illustrates this as "a person insisting on meeting a phenomenon face-to-face in order to understand its properties and procedural implications."

Another example is when the physician in the Section of Nephrology decides to reuse existing information because he both knows the context the information was created in and knows the patient trajectory. He knows the patient and has dictated the admittance report himself.

However as the number of contexts increases (for instance, expressed as a myriad of information sources or different departments), 'body-experience' becomes difficult to achieve. Texts that are to be used across contexts are objectified; meaning is detached from local contexts of interpretation (Smith 1990:211; Naur, 1985:254, Lam, 1995:989). Thus, 'reading' means to relate and translate - and understand - a text to a new context. This makes it imperative to participate in what Boland and Tenkasi (1995:351) denote as a 'perspective-taking' process, the ability or capability to take the knowledge of other communities of knowing into account. Consider for instance Pasi (Department of Cardiac and Thoracic Surgery) when he dictates the discharge letter, how he strategically picks out the one-month old discharge letter from the Department of Medicine and underscores that information produced a while ago might be important. As Pasi says about getting an overview of a case:

"The discharge letters from the Department of Medicine are very thorough. Reading them is a good way to obtain overview of a case."

As the Department of Medicine gives the patients a full examination prior to their surgery at Department of Cardiac and Thoracic Surgery this is hardly surprising. However it illustrates that Pasi takes another perspective when reading. He does not only produce the facts related to the current surgery in his discharge letter, but he also obtains the conditions for the surgery in the first place. Yet another example of perspective taking is when the physician in the Section of Nephrology uses the x-ray report. He sums up what he considers important and adds his own assessments thus translating the knowledge to the current context.

As discharge letters both sum up the history of the stay as well as make predictions and instructions for the future, they mirror how knowledge along the trajectory contributes in making the case predictable. The various contributions all add up to the stock of knowledge of the case and each contribution is evaluated against the trajectory knowledge, which ensures trust among the participants. 
Often physicians have to deal with patient trajectories characterized by high degrees of uncertainty and limited amounts of resources. Hunter (1991:28) underscores that:

"uncertainties of diagnosis and prognosis are fundamental to medicine, the methods physicians have devised to meet them are a fundamental part of medicine as well."

Consider for instance the following quote denoting an unplanned patient admittance:

"If the admittance report summary produced in the emergency department is a mix of previous case history (the reason for admittance and what the physician believed was the patient's problem) and then afterwards it appears to be something completely different, then the summary of the admittance report becomes completely useless and wrong - both in professional terms and in terms of being uninteresting for the one receiving the discharge letter to know what the admitting physician believed in that situation."

However, as a patient "develops" in the department, shaped by a rising or falling temperature, pulse, blood pressure, lab-results and x-ray diagnoses, the physicians get to know the patient. In addition, there are meetings where they discuss and assess further care and treatment. In this way, through collective sense making uncertainty is reduced and knowledge and trust is created.

"Based on new information in the process we discuss the case with pathologists, radiologists and hematologists as well as internally in our department...the outcome is regularly documented as a note in the patient record."

However, in spite of distributed knowledge of a case and trust among each other, physicians may experience uncertainties of diagnosis and prognosis. Such a situation is familiar for the Department of Oncology where the diagnosis is uncertain, the treatment is uncertain and is a matter of negotiation. Possible side effects are also difficult to predict.

The uncertainty and the whole process of negotiation is even reflected in the extensive discharge letter. The letter reflects the outcome of the negotiation process, this time between the patient, the assistant physician and the head physician where alternative assessment and treatment are discussed and where they try to make sense of an uncertain case. Still, however, the conclusion is not obvious. It underscores clearly that trajectory work is an interplay between efforts to control illness and contingencies (Strauss et al. 1985:19). In this particular case the physicians cannot lend themselves to experiences from routine trajectories, but must institute a search for options other than those they have already had experience with (ibid.:25).

Knowledge in these contexts is thus constructed and reconstructed in an ongoing process of targeted investigations, information gathering and a continuous struggle to keep a patient's trajectory 'on track' (Berg, 1997:127). This is a process that is supported by continuous discussions of the case; as one physician puts it:

"We are a kind of oral and assessing profession...It is important to have meetings, to discuss which treatment that is most important or correct and whether it should change or not... [because for chronic patients] we have medications that will not be effective within 3 months or 6 months time." (physician, Department of Rheumatology).

During such a process some of the discussions and their outcomes are stored as notes in the patient record, especially abnormal results and carefully improvised treatments. The discharge letter - the collective consensus that is the outcome of a trust-building process - then is the result of continuous negotiation of the meaning of the case. Uncertainty is minimized as far as possible as trust bridges. 


\section{Conclusion}

The paper shows that knowledge is fluid, shaped by processes of discussions and negotiations where knowledge and trust are interwoven. Work is needed to make information credible and trustworthy, for instance by interpreting assessing and validating the information in order to make it relevant and reusable for a given purpose at hand.

In order to consider information for reuse it appears that trust through predictability and overview is a key condition. However, as is shown, this is not always the case. Uncertainty in diagnosis and treatment strategies as well as fluctuating competence influences many work situations. Designing information systems under such conditions must take this into account. This underscores the point of moving beyond the point of just making information 'available.'

Firstly, as the analysis suggests, reusing information across contexts can be complicated. Whenever there are difficulties in understanding some information (for instance in the discharge letter), the information system should offer links or references back to previous related information (if existing) that more thoroughly elaborate the conditions for the current situation or assessment. From a general practitioner's point of view, for instance, this would mean potentially accessing information systems in hospitals such as electronic patient records, radiology systems or other specialized information systems facilitated by the proper link or reference.

Secondly, as the analysis has illustrated, overview and stability enhances potential for extensive reuse. In such situation it might be possible, promoted by an information system, to structure the knowledge in predefined categories, thus making it possible, on a more detailed level, to reuse some of these knowledge elements at a later stage. At the point of production of the information, it is accordingly possible to have reuse in mind and carefully adhere to the knowledge categories agreed on. It does not seem unlikely that such a strategy would also imply that the process of interpreting and validating information would become more structured, regulated and disciplined - as well as more transparent.

Thirdly, keeping track of what kind of knowledge has been reused and in what situations (e.g. checking off from a list), might demonstrate the usefulness of reusing certain trusted knowledge elements, for instance by counting how many times information has been reused and who has produced it.

Fourthly, as a part of their training, it is the assistant physicians that normally receive the patients, which sometimes results in worthless summaries in the admittance report (see the analysis section). Therefore it seems reasonable to demand that the electronic patient record should provide a feedback loop for the assistant physicians, offering a list with reference to the corresponding discharge letters. Consequently, the assistant physician would get an evaluation of his earlier assessments like insufficient description of status, disregarded things or wrong planning

\section{References}

Alvesson, M. (1995). Management of knowledge-intensive companies. Berlin: Walter de Gruyter.

Atkinson, P. (1995). Medical talk and medical work. Sage Publications.

Bachmann, R. (2001). Trust, power and control in trans-organizational relations. Organization Studies, 22 (2), pp. 337-365.

Berg, M. (1996). Practices of reading and writing: The constitutive role of the patient record in medical work. Sociology of Health and Illness, 18, pp. 499-524.

Berg, M. (1997). Rationalizing medical work: Decision-support techniques and medical practices. The MIT Press.

Berg, M. (1998). Medical work and the computer based patient record: A sociological perspective. Methods of Information in Medicine, 37, pp. 294-301.

Blackler, F. (1995). Knowledge, knowledge work and organizations: An overview and interpretation. Organization Studies, 16 (6), pp. 1021-1046. 


\section{The Role of Trust in Knowledge Management}

Blume, S.S. (1991). Insight and industry: On the dynamics of technological change in medicine. MIT Press.

Boland, Jr., R.J. \& Tenkasi, R.V. (1995). Perspective making and perspective taking in communities of knowing. Organization Science, 6 (4), pp. 350-372.

Brown, J.S. \& Duguid, P. (1991 ). Organisational learning and communities-of-practice: Toward a unified view of working, learning, and innovation. Organization Science, 2 (1), pp. 40-57.

Cicourel, A.V. (1990). The integration of distributed knowledge in collaborative medical diagnosis. In J. Galager, R.E. Kraut and C. Egido (eds.), Intellectual teamwork. Social and technological foundations of cooperative work (pp. 221-242). Hillsdale, NJ: Erlbaum.

Czarniawska, B. (1997). Narrating the organization. Chicago: The University of Chicago Press.

Davenport, T. \& Prusak, L. (1998). Working knowledge: How organizations manage what they know. Harvard Business School Press.

Giddens, A. (1991 ). The consequences of modernity. Cambridge: Polity Press.

Hardy, C., Phillips, N. \& Lawrence, T. (1998). Distinguishing trust and power in interorganizational relations: Forms and facades of trust. In C Lane and R. Bachmann (eds.), Trust within and between organizations: Conceptual issues and empirical applications, (pp. 64-87).

Hunter, K.M. (1991). Doctors' stories. The narrative structure of medical knowledge. Princeton University Press.

Klein, H. \& Myers, M. (1999). A set of principles for conducting and evaluating interpretive field studies in information systems. MIS Quarterly, 23 (1), pp. 67-94.

Knorr-Cetina, K. (1999). Epistemic cultures: How the sciences make knowledge. Harvard University Press.

Lam, A. (1997). Embedded firms, embedded knowledge: Problems of collaboration and knowledge transfer in global cooperative ventures. Organization Studies, 18 (6), pp. 973-996.

Lane, C. (1998). Introduction: Theories and issues in the study of trust. In C Lane and R. Bachmann (eds.), Trust within and between organizations: Conceptual issues and empirical applications (pp. 1-30).

Naur, P. (1985). Programming as theory building. Microprocessing and Microprogramming, 15, pp. 253-261.

Nonaka, I. \& Takeuchi, H. (1998). A theory of the firm's knowledge-creating dynamics. In A.D. Chandler jr., P. Hagstrøm and Ø. Sølvell (eds.), The dynamic firm. The role of technology, strategy, organization and regions. Oxford University Press.

Reiser, S. J. (1984). Creating form out of mass: The development of the medical record. In E. Mendelsohn (Ed.),Transformation and tradition in the sciences: Essays in honor of I. Bernard Cohen (pp. 303-316), New York: Cambridge University Press.

Smith, D.E. (1990). Texts, facts, and femininity: Exploring the relations of ruling. Routledge.

Strauss, A., Fagerhaugh, S., Suczek, B. \& Wiener, C. (1985). Social organization of medical work. Chicago: The University of Chicago Press.

Timmermans, S. \& Berg, M. (1997). Standardization in action: Achieving local universality through medical protocols. Social Studies of Science, 27, pp. 273-305.

Van House, N.A., Butler, M.H., \& Schiff, L.R. (1998). Cooperative knowledge work and practices of trust: Sharing environmental planning data sets. Proceedings of CSCW '98: The ACM Conference on Computer Supported Cooperative Work. Seattle, WA, November 14-18, pp. 335-343.

Van Maanen, J. (1988). Tales of the field. On writing ethnography. The University of Chicago Press.

von Krogh, G., Ichijo, K. \& Nonaka, I. (2000). Enabling knowledge creation: How to unlock the mystery of tacit knowledge and release the power of innovation. Oxford University Press.

Walsham, G. (1993). Interpreting information systems in organizations. John Wiley.

Zack, M.H. (1999). Managing codified knowledge. Sloan Management Review, 40 (4), pp. 45-58. 


\section{Biography}

Gunnar Ellingsen is an assistant professor at the Department of Telemedicine at the University of Tromso in Norway. He has worked several years as an IT consultant at the University Hospital of Northern Norway. He holds a PhD in Information Systems from the Norwegian University of Science and Technology. His research field centres on the design and use of electronic patient records in hospitals. His theoretical adherence is within the fields of Computer Supported Cooperative Work (CSCW) and Science and Technology Studies. He has published articles in Information and Organization, Journal of Computer Supported Cooperative Work and has accepted publications in Methods of Information in Medicine and Scandinavian Journal of Information Systems. 